\title{
Defining Patient Deterioration Through Acute Care and Intensive Care Nurses' Perspectives
}

\author{
Patrick Lavoie, RN, PhD candidate, Faculty of Nursing, Université de Montréal \\ Jacinthe Pepin, RN, PhD, Professor and Director of the Center for Innovation in Nursing \\ Education (CIFI), Faculty of Nursing, Université de Montréal \\ Marie Alderson, RN, PhD, Associate Professor, Faculty of Nursing, University de Montréal
}

The first author receives a doctoral scholarship from the Quebec Nursing Intervention Research Network (RRISIQ), funded by the Quebec Research Funds, Health (FRQS). The same organization funded the editing of this paper.

Corresponding author: Patrick Lavoie, patrick.lavoie.1@umontreal.ca

Coauthors: jacinthe.pepin@umontreal.ca, marie.alderson@umontreal.ca

Work address for all authors: C.P. 6128, succ. Centre-Ville, Montreal, QC, H3C 3J7

Keywords : Acute care nurses' perspective, Dimensional analysis, Intensive care nurses' perspective, Patient deterioration 


\begin{abstract}
Aim: To explore variations between acute care and intensive care nurses' understanding of patient deterioration according to their use of this term in published literature.

Background: Evidence suggests that nurses on wards do not always recognize and act upon patient deterioration appropriately. Even if resources exist to call for intensive care nurses' help, acute care nurses use them infrequently and the problem of unattended patient deterioration remains.
\end{abstract}

Design: Dimensional analysis was used as a framework to analyze papers retrieved in a nursing focused database.

Method: A thematic analysis of 34 papers (2002-2012) depicting acute care and intensive care unit nurses' perspectives on patient deterioration was conducted.

Findings: No explicit definition of patient deterioration was retrieved in the papers. There are variations between acute care and intensive care unit nurses' accounts of this concept, particularly regarding the validity of patient deterioration indicators. Contextual factors, processes and consequences are also explored.

Conclusions: From the perspectives of acute care and intensive care nurses, patient deterioration can be defined as an evolving, predictable and symptomatic process of worsening physiology toward critical illness. Contextual factors relating to acute care units appear as barriers to optimal care of the deteriorating patient. This work can be considered as a first effort in modeling the concept of patient deterioration, which could be specific to acute care units.

Relevance to Clinical Practice: The findings suggest it might be relevant to include subjective indicators of patient deterioration in track and trigger systems and educational efforts. Contextual factors impacting care for the deteriorating patient could be addressed in further attempts to deal with this issue. 


\section{Background}

On medical and surgical units outside the intensive care unit (ICU), the evidence suggests that nurses' recognition and care for deteriorating patients may be suboptimal (McQuillan et al., 1998; Massey et al., 2008; Quirke et al., 2011). In response to these findings, health care organizations around the world suggested the implementation of means to improve recognition and management of deteriorating patients on acute care units (ACU) (Hillman, 2004; Berwick et al., 2006; National Institute for Health and Clinical Excellence, 2007). We define ACU as inhospital settings where patients receive noncritical medical or surgical care.

Consequently, track and trigger systems were introduced. They consist of predetermined criteria indicating patient deterioration has reached a point where help of specialized staff is required. Little evidence supports their validity and reliability and they were found to show low sensitivity and low positive predictive values (Gao et al., 2007; Jansen and Cuthbertson, 2010). Additionally, specialized teams were formed as on-call resources in cases of patient deterioration on ACU. Medical emergency (Australia), outreach (UK) or rapid response (USA) teams bring together critical care expertise outside the ICU to help manage the care of deteriorating patients on ACU. Even if some patient outcomes were found to improve after their introduction, evidence regarding their impact remains scant (Esmonde et al., 2006; Ranji et al., 2007; Chan et al., 2010).

These tools and resources are used infrequently by nurses on ACU (Odell et al., 2009; Donohue and Endacott, 2010) and the issue of patient deterioration not being recognized or acted upon remains. Moreover, deteriorating patients are exposed to potential consequences such as ICU admission, cardiac arrest, and death (McGloin et al., 1999; Buist et al., 2004; Kause et al., 2004; National Confidential Enquiry into Patient Outcome and Death, 2005; National Patient Safety Agency, 2007).

A possible answer to this issue lies in their understanding of patient deterioration. Because 
ACU and ICU nurses evolve in different environments and care for patients with various levels of acuteness, they might hold different perspectives on what it means for a patient to deteriorate. To our knowledge, this precise question has not been examined yet, but has the potential to contribute to the dialogue between the two groups, for patients' benefit. Therefore, an analysis of their respective accounts on the concept of patient deterioration could be helpful in addressing the problem of patient deterioration in the acute care context.

\section{Aim and framework}

The purpose of this paper is to report on an exploration of ACU and ICU nurses' understanding of the concept of patient deterioration according to their use of this term in published literature. To reach this purpose, a dimensional analysis (Caron and Bowers, 2000) of patient deterioration was conducted. This form of analysis, rooted in symbolic interactionism, assumes that reality is "(1) socially constructed, (2) always defined from a particular perspective; and (3) contextually situated" (Caron and Bowers, 2000, p. 288). Dimensionalizing is the process whereby individuals select and organize dimensions or properties of a concept according to their relevance and significance in a particular context (Schatzman, 1991). Dimensional analysis aims at describing a concept's properties and how they vary according to certain perspectives by understanding the dimensionalization of a concept from the way it is used by certain people in particular contexts.

\section{Methods and sample}

To limit the literature sample to nurses' accounts of patient deterioration, a nursing database (CINAHL) was searched for publications between 2002 and 2012. We chose to search this single database because of its focus on literature specialized in nursing. The year range was pragmatically chosen to include papers written in the ten years before the date of the database search (2013). Using the keyword deterioration combined with ward or medical-surgical nursing 
and intensive care unit or critical care nursing, 129 papers written in English and available in full text were retrieved. A total of 74 texts comprised the term "patient deterioration" in their title or abstract. Papers where the concept was not discussed and where a nursing perspective wasn't acknowledged were excluded. The final sample consists of 26 papers identified with the database search. An additional 8 texts were included because of frequent quotations that were noted through the coding procedure that will be discussed in the next paragraph. No text was excluded based on its lack of scientific quality, since Caron and Bowers (2000) suggest that multiple sources of data should be used for dimensional analysis. Therefore, the results represent what was found in the nurses' discourse, but it wasn't the purpose of this work to verify the evidence base supporting their claims. A flowchart of texts selection is presented in Figure 1.

The explanatory matrix (Robrecht, 1995) was used as a tool to organize this analysis and represent findings. This tool portrays a concept's properties and associated processes and consequences, as a means to further develop understanding. In the texts of the sample, every excerpt regarding properties, dimensions, contexts, processes or consequences of patient deterioration was extracted and divided according to the perspectives (ACU or ICU nurses) that were presented. They were coded in an approach inspired by Paillé and Mucchielli's thematic analysis (Paillé and Mucchielli, 2012), an approach to qualitative data reduction. Themes that emerged through this process were grouped and classified under the four categories of the explanatory matrix. The coding-grouping procedure was completed separately for ICU nurses and ACU nurses and afterward compared to identify if dimensionalizing varied. As a means to ensure the rigor of the process, citations from the original papers were retrieved to support and illustrate our findings.

\section{Findings}

Throughout the final sample $(n=34)$, there was no explicit definition of the concept of 
patient deterioration, which suggests that authors assume a shared definition. Table 1 presents characteristics of included papers. Most papers were coming from the UK $(n=16)$ and reported research results $(n=18)$, mainly qualitative $(n=11)$. Nurses from the ICU wrote most papers $(n=22)$ and some authors $(n=12)$ report on ACU nurses' sayings using interview quotes. Caron and Bowers (2000) suggest exercising caution with such results, as authors might impose their own conception on to people they are writing about. Figure 2 presents the explanatory matrix resulting from our analysis.

\section{Properties and Dimensions}

Four properties of patient deterioration were identified. From the way it is addressed in the sample, patient deterioration appears as an evolving, physiological, predictable and symptomatic phenomenon. Table 2 presents a summary of the properties of patient deterioration and their dimensionalization by ACU and ICU nurses with citations to support these claims.

The evolving property of patient deterioration was identified through use of terms such as “deterioration trajectory" (Donohue and Endacott, 2010, p. 15), "patient progress" (Johnstone et al., 2007, p. 221) or "further deterioration" (Barbetti and Choate, 2003, p. 47; Leach et al., 2012, p. 65). Adjectives used with deterioration, such as early, late, rapid or slow, indicate that it progresses through time. The acuteness of the patient state also appears to evolve, as authors refer to a movement toward a compromised or critical condition. For example, Andrews and Waterman (2005) explain that some patients "are in danger of becoming critically ill" (p. 474) while Cioffi et al. (2010) describe "the compensatory period before [deteriorating patients] become markedly compromised" (p. 190). No difference between ICU and ACU nurses' accounts of this property was noted.

Patient deterioration is solely referred to as a physiological phenomenon. ACU and ICU nurses believe that it is a "disordered physiology" (Sharpley and Holden, 2004, p. 102), the 
consequence of a "malfunctioning of the body's homeostatic mechanism" (Liaw et al., 2011, p. 298) or the effect of "physiological abnormalities" (Barbetti and Choate, 2003, p. 47; Endacott et al., 2007, p. 104). Some authors explain that observation of physiological parameters is a key to identify patient deterioration (Johnstone et al., 2007; Donohue and Endacott, 2010). Additionally, patient deterioration is often paralleled with illnesses and diseases, whether acute (Massey et al., 2008; Jonsson et al., 2011) or critical (Sharpley and Holden, 2004; Cox et al., 2006; Jones et al., 2010; Odell et al., 2010). Critical illness and deterioration are used interchangeably, for example when Ryan et al. (2004) explain that abnormal physiological observations are "the most important manifestation of existing or developing critical illness" (p. 1186) and are a useful warning "of potential patient deterioration" (p. 1186). Moreover, the physiological property is exemplified in ICU nurses' references to the Intensive Care Society's levels of care (2002) that suggest classifying patients according to the type of organ support they require (e.g. respiratory, renal, cardiovascular, or multiple organ support). This reference wasn't present in ACU nurses' account.

The predictable property was inferred from multiple references to risk factors associated with patient deterioration. Patients who recover from critical illness (Endacott et al., 2009), namely those recently discharged from an ICU (Mailey et al., 2006), may face a higher risk of deterioration, along with "emergency admissions, patients having had a major surgery, $[\ldots]$ or those with pre-existing respiratory, cardiac or renal disease" (Sharpley and Holden, 2004, p. 100101). Other risk factors such as "age, gender, number of organ failures at the first admission, respiratory support-mechanical ventilation and multiple vasoactive medications" (Johnstone et al., 2007, p. 220) increase the possibility of deteriorating.

In addition, deterioration is described as a precursor to adverse events. An important number of studies within the medical field examined patients' trajectory before ICU admission, 
cardiac arrest or death (Schein et al., 1990; Goldhill et al., 1999; Hodgetts et al., 2002). As authors conclude that clinical signs predicting patient deterioration were present for hours before most adverse events, they came to agree that it is possible to anticipate and prevent them. Consequently, patient deterioration is expected from risk factors and also predicts impending critical illness or adverse events.

The symptomatic property of patient deterioration was the most frequently encountered and the one where most dimensionalizing was perceived. Relying on the above-mentioned medical studies, all papers in the sample discuss at some point the presence of clinical signs coinciding with patient deterioration. Abnormal vital signs, including blood pressure, respiratory rate and heart rate, are considered significant indicators that a patient is deteriorating. Other indicators consist of objective physiological signs that can be discovered with physical assessment. Whether they are associated with respiratory, cardiovascular, neurological, renal, or thermoregulatory abnormalities, they are said to be present alone or in combination when a patient is deteriorating.

Vital signs and objective physiological criteria are included in track and trigger systems. The abnormality of these observations allows the calculation of a score that quantifies patient deterioration. It indicates the severity of the overall patient condition (Donohue and Endacott, 2010; Jonsson et al., 2011; Leach et al., 2012) and when it increases, it indicates that a patient is deteriorating (Oakey and Slade, 2006). In other words, "the further the deviation from physiological norm, the higher the score and the sicker the patient" (Sharpley and Holden, 2004, p. 99). These tools comprise a trigger that signifies when a score is sufficiently high to justify the involvement of critical care staff. According to ICU nurses, track and trigger tools are reliable and sensitive for early identification of deterioration (Sharpley and Holden, 2004; Jonsson et al., 2011). In contrast, ACU nurses believe that objective signs are not always present or sensitive 
(Cioffi et al., 2010; Cioffi et al., 2009). Trigger levels are said to be too high (Oakey and Slade, 2006) and calculation of a deterioration score might be misleading for certain patients living with chronic illness for example (Donohue and Endacott, 2010).

Thus, ACU nurses tend to use subjective signs to recognize patient deterioration (Cioffi, 2000a; Cioffi, 2000b; Cioffi et al., 2009). They are described as "subtle cues that arouse the suspicion of nurses but are difficult to quantify" (Cioffi et al., 2010) and are used whenever a patient's condition becomes worrisome. According to Cioffi et al. (2009), these subjective signs are among the most frequently used criteria to recognize deterioration on the ward and are detected even before objective signs begin to show. Further exploration of the "patient of concern" criterion revealed that it comprised respiratory, neurological and circulatory symptoms and others signs such as a new or escalating pain, unexpected recovery trajectory or new observation/symptom, including patients feeling impending doom (Cioffi et al., 2009). When critical care nurses were presented with these signs, they judged them necessary but not sufficient to validly assess early clinical deterioration (Cioffi et al., 2010). This reiterates the confidence ICU nurses have in objective signs, even if ACU nurses believe they are late indicators of patient deterioration. The pervasiveness of the symptomatic property of patient deterioration in the nursing literature can be seen in all the papers reporting the implementation of resources to identify and act upon indicators of patient deterioration (Barbetti and Choate, 2003; Mailey et al., 2006; Oakey and Slade, 2006; Carter, 2007).

\section{Context}

ACU and ICU nurses report several contextual factors that affect ACU nurses' perspective on patient deterioration, which can be personal, organizational, professional, technological, or related to the patient. These data almost exclusively concerned the ACU setting and there was little indication of how the ICU context could affect nurses in their understanding 
of patient deterioration. The only disclosed ICU specificity was the availability of sophisticated monitoring equipment that "can give data that permit analysis of key circulatory functions and the anticipation of deterioration" (Cottis et al., 2003, p. 301).

At the personal level, nurses' knowledge and skills are influential in their reaction to patient deterioration. Physiology (Cottis et al., 2003; Cioffi et al., 2010) and pathophysiology (Liaw et al., 2011) were described as important to know, but experiential knowledge appeared central, since knowing a patient and work experience with similar situations influence the appropriateness of nurses' decision-making (Cioffi, 2000a; Kenward and Hodgetts, 2002; Endacott and Westley, 2006; Wheatley, 2006; Gazarian et al., 2010). Yet, ACU nurses are allegedly less experienced with deteriorating patients compared to ICU nurses who have "years of practice in assessment and intervention with critically ill patients and [understand] the dynamic continuum ranging from critical but stable to life-threatening situations" (Leach et al., 2012, p. 68). Furthermore, the indispensability of ACU nurses' clinical and communicational skills is stated (Andrews and Waterman, 2005; Cox et al., 2006; Higginson and Jones, 2009; Jones et al., 2010), sometimes in light of their educational needs (Kenward and Hodgetts, 2002; Donohue and Endacott, 2010; Liaw et al., 2011). In fact, critical care education on patient deterioration is said to be necessary for all nurses throughout the hospital (Cox et al., 2006; Higginson and Jones, 2009).

At the organizational level, the ACU is described as a busy and noisy environment (Odell et al., 2009; Ryan et al., 2004) where staff works under extreme pressure (Donohue and Endacott, 2010). With limited ICU bed availability and faster or premature discharges (Endacott et al., 2009; Liaw et al., 2011), patients at risk of deterioration are present across many ACU (Sharpley and Holden, 2004; Johnstone et al., 2007; Cioffi et al., 2010). Increased workload combined with lack of human resources put these patients at a disadvantage compared to those in 
the ICU (Mailey et al., 2006; Massey et al., 2008). This situation undermines the balance between patients' needs and resources availability and impedes nurses' capacity to identify patient deterioration and mobilize bedside support. Ward policies and specific practices impact the management of patient deterioration as well, with hierarchical communication issues and when "patients [need] to "qualify" for assessment by meeting criteria" (Endacott et al., 2007, p. 103).

At the professional level, nurses on ACU deal with variability in staff and skill mixes (Endacott et al., 2007; Odell et al., 2009). The delegation of nursing tasks seems to be fostered by the inclusion of health care assistants (HCA) in staffing models. While they make the vast majority of observations and spend more time than nurses with patients, HCA fail to identify deterioration (Wheatley, 2006) because they are not aware of the importance and implications of abnormal findings (Sharpley and Holden, 2004). Besides, ACU nurses are also facing limited physicians' expertise availability (Johnstone et al., 2007), because of multiple demands on medical time (Endacott et al., 2007) and junior doctors' inexperience (Donohue and Endacott, 2010; Mailey et al., 2006; Odell et al., 2009). The combination of these factors renders a difficult professional context for nursing practice, where "the priority of qualified ACU nurses appears to have changed from the basics of hands-on patient care to delegation of tasks, answering phones and liaising with doctors" (Wheatley, 2006, p. 120).

At the technological level, ACU staff relies heavily on equipment to measure patients' physiological parameters, even if it is fallible (Cox et al., 2006; Gazarian et al., 2010) and can give erroneous data. High-tech equipment, like patient monitors or invasive devices of the ICU, are not always available on ACU (Jonsson et al., 2011). It is suggested that the constant monitoring of patient with these devices could improve the detection of deterioration. Yet, some of the features of these devices (e.g. false alarms) might be incompatible with ACU (Burgess et 
al., 2009).

At the patient level, there is an agreement that the "the aging population, increased complexity of medical interventions and shorter length of hospital inpatient stays have meant that patients in hospital (sic) are at an increased risk of becoming ill” (Higginson and Jones, 2009, p. 456). Individual characteristics such as different languages, different cultures or impaired cognition can compromise the early recognition of the deteriorating patient (Cioffi et al., 2009). Conversely the presence of family members can be helpful to recognize subtle alteration of patients' level of consciousness, which can indicate deterioration (Minick and Harvey, 2003).

\section{Processes}

Four processes associated with patient deterioration were described in the sample: surveillance, recognition, referral and response. Surveillance of patient deterioration is associated with patient assessment and monitoring. It is a precursor to the recognition process since "the taking of patient observations and its utilization as a part of patient assessment is essential if indicators of patient deterioration are to be detected" (Wheatley, 2006, p. 119). It was suggested that taking observations is a routine task of low priority (Odell et al., 2009), delegated to HCA most of the time (Ryan et al., 2004; Wheatley, 2006). Observations and their documentation are poor (Ryan et al., 2004; Wheatley, 2006; Jonsson et al., 2011; Ludikhuize et al., 2012; Pantazopoulos et al., 2012) and ICU nurses say that ACU nurses rely on visual observation (Donohue and Endacott, 2010) instead of using manual skills (Wheatley, 2006). ICU nurses believe it is necessary to increase surveillance and vigilance and suggest track and trigger systems or outreach teams to do so (Oakey and Slade, 2006; Leach et al., 2012).

Recognition of patient deterioration is the result of the interpretation of clinical data (Donohue and Endacott, 2010) when nurses appreciate the clinical urgency of a patient's status (Massey et al., 2008). Cognitive processes used by ACU nurses, like pattern recognition or 
intuition (Cioffi, 2000b; Cox et al., 2006; Minick and Harvey, 2003), are the basis for interpretation and precursors to clinical judgment. Track and trigger systems were introduced to help recognize patient deterioration (Sharpley and Holden, 2004) and give weight to nurses' assessment (Ryan et al., 2004), but not to replace clinical judgment (Johnstone et al., 2007; Odell et al., 2009).

Referral of the deteriorating patient happens when ACU nurses communicate with other clinicians to get help by conveying a large volume of complex information (Odell et al., 2009). In the sample, authors assert that ACU nurses do not communicate effectively or clearly enough (Featherstone et al., 2008). Even if they are aware that they need quantifiable evidence of patient deterioration to convince doctors (Johnstone et al., 2007; Featherstone et al., 2008; Cioffi et al., 2009), they use social or everyday language rather than medical language (Andrews and Waterman, 2005) and do not always communicate relevant or necessary information (Donohue and Endacott, 2010). Social language is difficult for doctors to understand (Andrews and Waterman, 2005) and does not carry the urgency of the situation (Featherstone et al., 2008). Besides, ACU nurses seem to lack confidence and experience fear of looking stupid when calling doctors (Cioffi, 2000b; Cioffi et al., 2009). They would sometimes wait for the patient's condition to worsen (Cioffi et al., 2010) or ask for the assistance of fellow nurses (Cox et al., 2006; Gazarian et al., 2010) to make sure they are doing the right thing. Once again, track and trigger systems are proposed as a means to improve the referral of deteriorating patients to the right professional in a timely manner (Ryan et al., 2004; Sharpley and Holden, 2004), as well as a structured approach to communication (Featherstone et al., 2008).

Response to patient deterioration comprises interventions and treatments aimed at stopping or reversing the process of deterioration. Although ACU nurses need to decide when to intervene (Johnstone et al., 2007), critical care teams sent to the bedside direct most responses. 
There are diverging opinions on the quality of care prior to critical care teams' arrival, some believing that "[ward staff] are actually running around trying their best to do an awful lot" (Donohue and Endacott, 2010, p. 13) and others reiterating that suboptimal care is common (Sharpley and Holden, 2004).

\section{Consequences}

According to texts in the sample, adverse patient events, such as cardiac arrest or death, are the main consequence of patient deterioration. It was noticed that ICU nurses mainly mentioned ICU admission as a consequence of patient deterioration. A few complications, like pulmonary oedema (Barbetti and Choate, 2003), severe sepsis (Carter, 2007), or massive haemorrhage (Cioffi et al., 2009), were also stated.

Another consequence of patient deterioration is the involvement of specialized practitioners, that is to say physicians and critical care nurses. The former intervene by reviewing the deteriorating patient (Cioffi et al., 2009; Barbetti and Choate, 2003). The latter become involved to give information and advice on patient management (Barbetti and Choate, 2003; Ryan et al., 2004) and share skills (Sharpley and Holden, 2004; Wheatley, 2006; Leach et al., 2012). ACU nurses seem to be relieved when specialized practitioners take the lead and direct their activities (Cox et al., 2006; Donohue and Endacott, 2010). They express trust, reliance and a positive attitude toward expert help and feel reassured by assistance (Donohue and Endacott, 2010; Pantazopoulos et al., 2012). Even if they are seen as "being able to get things done, having knowledge and skills to take charge of the situation" (Donohue and Endacott, 2010, p. 14), ICU nurses consider that the ACU team keeps the responsibility of the patient. They are only there to bring their expertise to the bedside and leave once the patient's condition improves (Carter, 2007), unless an admission to the ICU is evident (Donohue and Endacott, 2010).

According to these results and as depicted in Figure 2, ACU and ICU nurses view patient 
deterioration as an evolving, physiological, predictable and symptomatic phenomenon. Because it can lead to adverse patients event, ACU nurses are expected to survey, recognize and respond to patient deterioration, while they are to refer the deteriorating patient to specialized practitioners. Of note, the context of the ACU (organizational, professional and technological factors) appears as a barrier to optimal care of the deteriorating patient, while personal factors and patient factors are also influencing the care processes.

\section{Conclusion}

We presented the results of a dimensional analysis of patient deterioration in the nursing literature. It brought forward the properties of this concept, which are relatively similar from ICU to ACU nurses' perspectives. However, the way they recognize this phenomenon varies and they hold different opinions on the validity, specificity and representativeness of the indicators of patient deterioration. Besides, contextual factors seem to contribute to the recognition and intervention problem described above.

To our knowledge, this is the first dimensional analysis of patient deterioration. Since no definition was retrieved in the sample, the properties identified through this analysis suggest ACU and ICU nurses define it as an evolving, predictable and symptomatic process of worsening physiology toward critical illness. It should be noted that dimensional analysis, as a framework to analyze published literature, was found to be of interest in addressing an issue implying professional groups evolving in different contexts. The exploration of this concept through an interactionist perspective has brought a wide systemic view of this phenomenon that may partly explain why ACU nurses do not always recognize or act on patient deterioration as ICU nurses would. The resulting explanatory matrix (Figure 2) can be considered as a first theoretical effort in modelling the concept of patient deterioration. It is desirable that this first version of a model be validated and refined through further research exploring ICU and ACU nurses' perspective 
and how contextual elements are influential.

In the sample, patient deterioration was conceptualized as a solely physiological phenomenon. Before starting this analysis, we were under the impression that we would stumble upon other forms of deterioration: social, psychological, spiritual, or functional, for instance. Furthermore, we expected nurses to question the biomedical perspective and refer to a conception of patient deterioration from a nursing standpoint (Risjord, 2010). Even though we were not specifically searching for it, the patient's perspective was never mentioned throughout the sample. This raises questions about how the nursing perspective or philosophy could impact the conception of patient deterioration.

In the papers included in the sample, data almost exclusively described patient deterioration in the ACU, mostly from an ICU nurse's perspective. Therefore, we hypothesize that ICU nurses' perspective might overshadow ACU nurses' one. This might be explained by the origin of the interest in this issue, which was raised by studies conducted by medical researchers of patient trajectory prior to ICU admission or cardiac arrest (Schein et al., 1990; Goldhill et al., 1999; Hodgetts et al., 2002). Questioning the quality of care of deteriorating patients on ACU seems to have brought the focus solely on this environment. Nevertheless, this dimensional analysis reveals the gap in understanding how ICU nurses' conception of patient deterioration is influenced by the ICU context. It also brings to light the idea that this concept might be used to describe an ACU-specific phenomenon. This could be explained by the fact that ICU nurses care for critically ill patients that have already deteriorated.

Further research is needed to address gaps in knowledge on patient deterioration and to address limitations of our own work. Since this analysis revealed that patient deterioration and critical illness are used interchangeably, including the second term in the search strategy would probably have provided other relevant papers that weren't included. Other databases could be 
searched to extend the span of this work. Moreover, data obtained through empirical research methods could contribute to the comprehensiveness of this analysis. This work can be considered as a first step leading to a hybrid method (Schwartz-Barcott and Hesook, 2000) in the development of the concept of patient deterioration.

\section{Implications for practice}

The premise that guided this work was the hypothesis that ICU and ACU nurses' could hold different perspectives on patient deterioration, since they might be influenced by their respective contexts. The most important difference was found in the symptomatic property, when the perception of the validity of the criteria used to recognize patient deterioration varies from ICU to ACU nurses. The ICU nurses' emphasis on objective criteria, which are quantifiable, may be linked to their appropriateness and acceptability to medical colleagues. It is interesting though that some track and trigger systems comprise a "nurse's concern or worry" criterion (Santiano et al., 2009) that gives credit to ACU nurses' intuition. Because knowledge exists on the symptoms that give rise to nurses' concern, they could be included in such tools or addressed in educational efforts to improve nurses' or nursing students' recognition and intervention skills in patient deterioration situations.

Previous efforts towards patient deterioration have focused on the four processes that were described above. Besides, contextual factors impacting care for the deteriorating patient could be of interest for nurse clinicians, educators and administrators. It appears necessary to pursue educational endeavours to develop ACU nurses' expertise in critical care and to sensitize ICU nurses to their concern. Experiential learning methods, such as simulation or case studies, could be of help considering the argument that ICU nurses' experience with such situations is influential for the quality of their care. It also appears relevant to question actual policies and 
staffing models to explore new venues for better attendance to deteriorating patients.

Furthermore, there is still a need to investigate the possibility of making available technologies that could impact recognition of patient deterioration. Patient factors are also interesting in that they indicate new elements that need to be taken into account to address this issue. 


\section{References}

Andrews T, Waterman H. (2005). Packaging: A grounded theory of how to report physiological deterioration effectively. Journal of Advanced Nursing; 52: 473-481.

Barbetti J, Choate K. (2003). Intensive care liaison nurse service: Implementation at a major metropolitan hospital. Australian Critical Care; 16: 46-52.

Berwick DM, Clakins DR, Mccannon J, Hackbart AD. (2006). The 100000 lives campaign: Setting a goal and a deadline for improving health care quality. Journal of the American Medical Association; 295: 324-327.

Buist M, Bernard S, Nguyen TV, Moore G, Anderson J. (2004). Association between clinically abnormal observations and subsequent in-hospital mortality: A prospective study. Resuscitation; 62: 137-141.

Burgess LPA, Herdman TH, Berg BW, Feaster WW, Hebsur S. (2009). Alarm limit settings for early warning systems to identify at-risk patient. Journal of Advanced Nursing; 65: 18441852.

Caron CD, Bowers BJ (2000). Methods and application of dimensional analysis: A contribution to concept and knowledge development in nursing. In: Rodgers, B. L. \& Knafl, K. A. (eds) Concept development in nursing: Foundations, techniques, and applications. 2nd ed. Philadelphia, PA: Saunders.

Carter C. (2007). Implementing the severe sepsis care bundles outside the ICU by outreach. Nursing in Critical Care; 12: 225-230.

Chan PS, Jain R, Nallmothu BK, Berg RA, Sasson C. (2010). Rapid response teams: A systematic review and meta-analysis. Archives of Internal Medicine; 170: 18-26.

Cioffi J. (2000a). Nurses' experiences of making decisions to call emergency assistance to their patients. Journal of Advanced Nursing; 32: 108-114.

Cioffi J. (2000b). Recognition of patients who require emergency assistance: A descriptive study. Heart \& Lung; 29: 262-268.

Cioffi J, Conway R, Everist L, Scott J, Senior J. (2009). 'Patients of concern' to nurses in acute care settings: A descriptive study. Australian Critical Care; 22: 178-186.

Cioffi J, Conway R, Everist L, Scott J, Senior J. (2010). 'Changes of concern' for detecting potential early clinical deterioration: A validation study. Australian Critical Care; 23: 188-196.

Cottis R, Magee N, Higgins DJ. (2003). Haemodynamic monitoring with pulse-induced contour cardiac output (PiCCO) in critical care. Intensive and Critical Care Nursing; 19: 301-307. 
Cox H, James J, Hunt J. (2006). The experiences of trained nurses caring for critically ill patients within a general ward setting. Intensive and Critical Care Nursing; 22: 283-293.

Donohue LA, Endacott R. (2010). Track, trigger and teamwork: Communication of deterioration in acute medical and surgical wards. Intensive and Critical Care Nursing; 26: 10-17.

Endacott R, Elliott S, Chaboyer W. (2009). An integratrive review and meta-synthesis of the scope and impact of intensive care liaison and outreach services. Journal of Clinical Nursing; 18: 3225-3236.

Endacott R, Kidd T, Chaboyer W, Edington J. (2007). Recognition and communication of patient deterioration in a regional hospital: A multi-methods study. Australian Critical Care; 20: 100-105.

Endacott R, Westley M. (2006). Managing patients at risk of deterioration in rural hospitals: a qualitative study. Australian Journal of Rural Health; 14: 275-279.

Esmonde L, Mcdonnell A, Ball C, Waskett C, Morgan R, Rashidian A, Bray K, Adam S, Harvey S. (2006). Investigating the effectiveness of critical care outreach services: A systematic review. Intensive Care Med; 32: 1713-1721.

Featherstone P, Chalmers T, Smith GB. (2008). RSVP: A system for communication of deterioration in hospital patients. British Journal of Nursing; 17: 860-864.

Gao H, Mcdonnell A, Harrison DA, Moore T, Adam S, Daly K, Esmonde L, Goldhill DR, Parry GJ, Rashidian A, Subbe CP, Harvey S. (2007). Systematic review and evaluation of physiological track and trigger warning systems for identifying at-risk patients on the ward. Intensive Care Medicine; 33: 667-679.

Gazarian PK, Henneman EA, Chandler GE. (2010). Nurse decision making in the prearrest period. Clinical Nursing Research; 19: 21-37.

Goldhill DR, White SA, Sumner A. (1999). Physiological values and procedures in the 24 hours before ICU admission from the ward. Anaesthesia; 54: 529-534.

Higginson R, Jones B. (2009). Respiratory assessment in critically ill patients: Airway and breathing. British Journal of Nursing; 18: 456-461.

Hillman K. (2004). Expanding intensive care medicine beyond the intensive care unit. Critical Care; 8: 9-10.

Hodgetts TJ, Kenward G, Vlackonikolis I, Payne S, Castle N, Crouch R, Ineson N, Shaikh L. (2002). Incidence, location and reasons for avoidable in-hospital cardiac arrest in a district general hospital. Resuscitation; 54: 115-123.

Jansen JO, Cuthbertson BH. (2010). Detecting critical illness outside the ICU: The role of track and trigger systems. Current Opinion in Critical Care; 16: 184-190. 
Johnstone CC, Rattray J, Myers L. (2007). Physiological risk factors, early warning scoring systems and organizational changes. Nursing in Critical Care; 12: 219-224.

Jones B, Higginson R, Santos A. (2010). Critical care: Assessing blood pressure, circulation and intravascular volume. British Journal of Nursing; 19: 153-159.

Jonsson T, Jonsdottir J, Möller AD, Baldursdottir L. (2011). Nursing documentation prior to emergency admissions to the intensive care unit. Nursing in Critical Care; 16: 164-169.

Kause A, Smith G, Prytherch D, Parr M, Falbouris A, Hillman K. (2004). A comparison of Antecedents to Cardiac Arrests, Deaths, and EMergency Intensive care Admissions in Australia and New Zealand, and the United Kingdom - The ACADEMIA study. Resuscitation; 62: 275-282.

Kenward G, Hodgetts T. (2002). Nurse concern: A predictor of patient deterioration. Nursing Times; 98: 38-39.

Leach LS, Kagawa F, Mayo A, Pugh C. (2012). Improving patient safety to reduce preventable deaths: The case of a California safety net hospital. Journal of Healthcare Quality: Promoting Excellence in Healthcare; 34: 64-76.

Liaw SY, Scherpbier A, Klainin-Yobas P, Rethans JJ. (2011). A review of education strategies to improve nurses' roles in recognizing and responding to deteriorating patients. International Nursing Review; 58: 296-303.

Ludikhuize J, Smorenburg SM, De Rooij SE, De Jonge E. (2012). Identification of deteriorating patients on general wards: Measurement of vital parameters and potential effectiveness of the Modified Early Warning Score. Journal of Critical Care; 27: 424.e427-424.e413.

Mailey J, Digiovine B, Baillod D, Gnam G, Jordan J, Rubinfeld I. (2006). Reducing hospital standardized mortality rate with early interventions. Journal of Trauma Nursing; 13: 178182.

Massey D, Aitken LM, Wendy C. (2008). What factors influence suboptimal ward care in the acutely ill ward patient? Australian Critical Care; 21: 127-140.

Mcgloin H, Adam S, Singer M. (1999). Unexpected deaths and referrals to intensive care of patients on general wards. Are some cases potentially avoidable? Journal of the Royal College of Physicians London; 33: 255-259.

Mcquillan P, Pilkington S, Allan A, Taylor B, Short S, Morgan G, Nielsen M, Barrett D, Smith G. (1998). Confidential inquiry into quality of care before admission to intensive care. British Medical Journal; 316: 1853-1858.

Minick P, Harvey S. (2003). The early recognition of patient problems among medical-surgical nurses. MEDSURG Nursing; 12: 291-297. 
National Confidential Enquiry into Patient Outcome and Death (2005). An acute problem? London, NCEPOD.

National Institute for Health and Clinical Excellence (2007). Acutely ill patients in hospital: recognition of and response to acute illness in hospital. London, UK, National Institute for Health and Clinical Excellence.

National Patient Safety Agency (2007). Safer care for the acutely ill patient: Learning from serious incidents. London, UK, National Patient Safety Agency.

Oakey RJ, Slade V. (2006). Physiological observation track and trigger system. Nursing Standard; 20: 48-54.

Odell M, Gerber K, Gager M. (2010). Call 4 Concern: Patient and relative activated critical care outreach. British Journal of Nursing; 19: 1390-1395.

Odell M, Victor C, Oliver D. (2009). Nurses' role in detecting deterioration in ward patients: Systematic literature review. Journal of Advanced Nursing; 65: 1992-2006.

Paillé P, Mucchielli A (2012). L'analyse qualitative en sciences humaines et sociales. Paris, Armand Colin.

Pantazopoulos I, Tsoni A, Kouskouni E, Papadimitriou L, Johnson EO, Xanthos T. (2012). Factors influencing nurses' decisions to activate medical emergency teams. Journal of Clinical Nursing; 21: 2668-2678.

Quirke S, Coombs M, Mceldowney R. (2011). Suboptimal care of the acutely unwell ward patient: A concept analysis. Journal of Advanced Nursing; 67: 1834-1845.

Ranji SR, Auerbach AD, Hurd CJ, O'rourke K, Shojania KG. (2007). Effects of rapid response systems on clinical outcomes: Systematic review and meta-analysis. Journal of Hospital Medicine; 2: 422-432.

Risjord M (2010). Nursing knowledge: Science, practice, and philosophy. Chichester, West Sussex, Blackwell.

Robrecht LC. (1995). Grounded theory: Evolving methods. Qualitative Health Research; 5: 169177.

Ryan H, Cadman C, Hann L. (2004). Critical care: Setting Standards for assessment of ward patients at risk of deterioration. British Journal of Nursing; 13: 1186-1190.

Santiano N, Young L, Hillman K, Parr M, Jayasinghe S, Baramy LS, Stevenson J, Heath T, Chan C, Claire M, Hanger G. (2009). Analysis of medical emergency team calls comparing subjective to "objective" call criteria. Resuscitation; 80: 44-49. 
Schatzman L (1991). Dimensional analysis: Notes on an alternative approach to the grounding of theory in qualitative research. In: Maines, K. R. (ed) Social organization and social process essays in honor of Anselm Strauss. New York, NY: Aldine De Gruyter.

Schein RM, Hazday N, Pena M, Ruben BH, Sprung CL. (1990). Clinical antecedents to inhospital cardiopulmonary arrest. Chest; 98: 1388-1392.

Schwartz-Barcott D, Hesook SK (2000). An expansion and elaboration of the hybrid model of concept development. In: Rodgers, B. L. \& Knafl, K. A. (eds) Concept development in nursing: Foundations, techniques and applications. Philadelphia, PA: Saunders.

Sharpley JT, Holden JC. (2004). Introducing an early warning scoring system in a district general hospital. Nursing in Critical Care; 9: 98-103.

Wheatley I. (2006). The nursing practice of taking level 1 patient observations. Intensive and Critical Care Nursing; 22: 115-121. 
Figure 1. Flowchart of texts selection

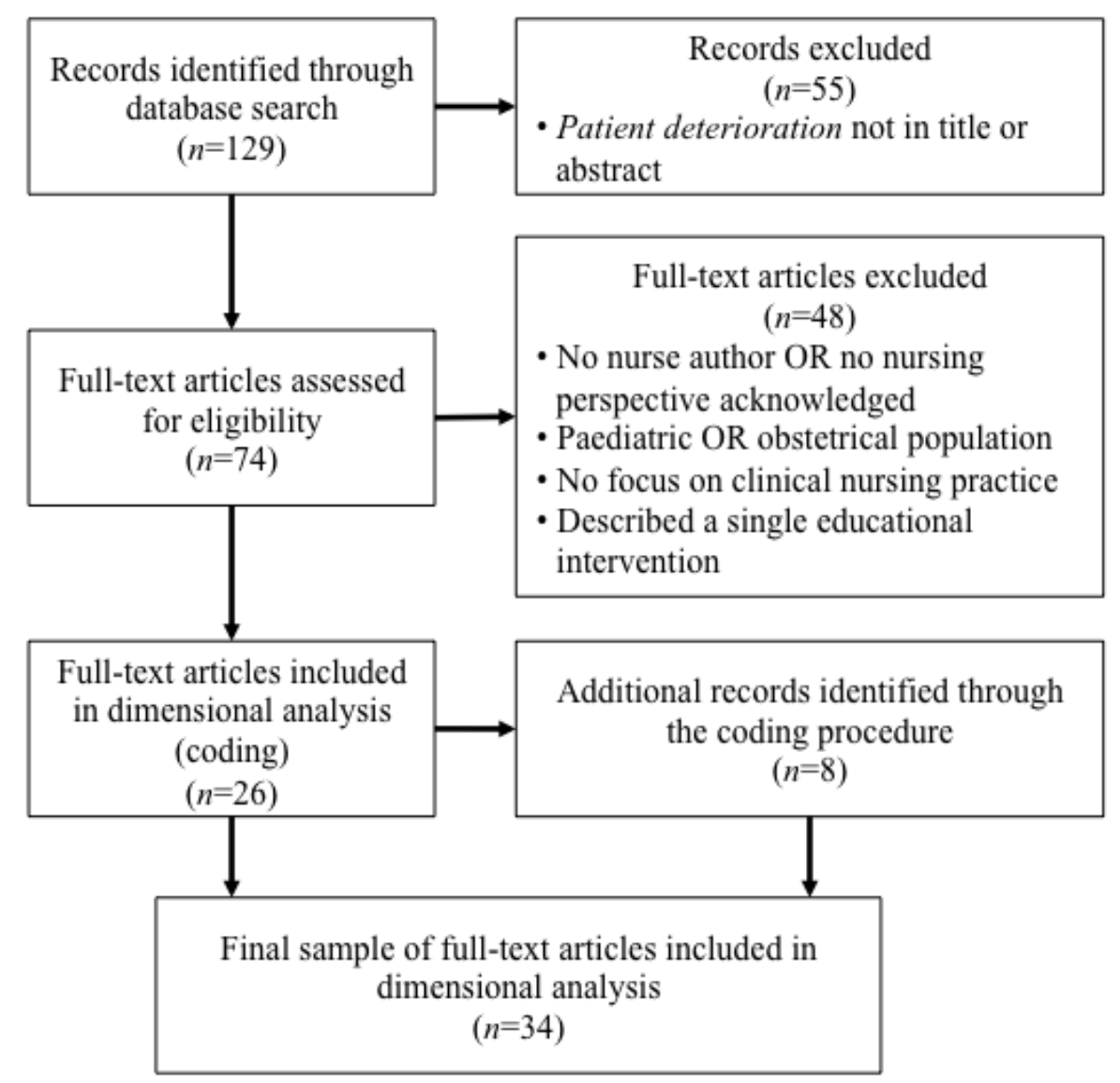


Figure 2. Explanatory matrix of patient deterioration from ACU and ICU nurses' perspectives

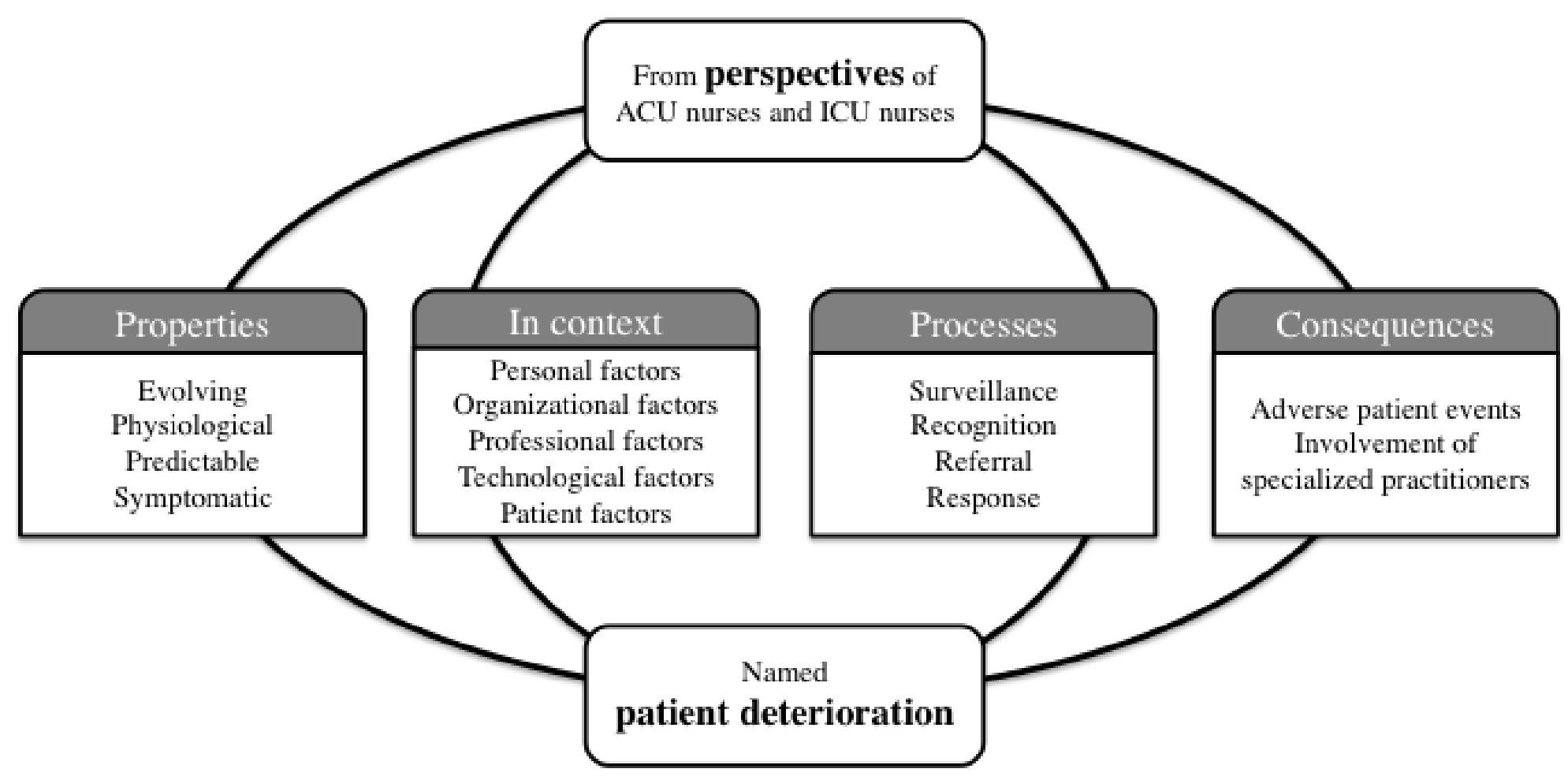




\section{Impacts}

\section{What is know about the subject}

- Even if knowledge exists on how to recognize and respond to patient deterioration, care for the deteriorating patients remains suboptimal.

- Nurses on acute care units infrequently use resources designed to help them recognize and intervene upon patient deterioration.

- Acute care nurses and intensive care nurses evolve in different contexts, which could influence their conception of patient deterioration.

\section{What this paper contributes}

- From ACU and ICU nurses' perspectives, patient deterioration can be defined as an evolving, predictable and symptomatic process of worsening physiology toward critical illness. However, there are divergences in their beliefs concerning the validity of patient deterioration indicators.

- A systemic view of patient deterioration has been developed through inclusion of contextual factors, processes and consequences associated with this concept.

- The preliminary definition of contextual factors impacting care of the deteriorating patient on acute care units suggests new venues to deal with this problem. 
Table 1. Characteristics of papers in the sample

\begin{tabular}{ll}
\hline Country & \\
\hline Australia & 7 \\
UK & 14 \\
USA & 5 \\
Australia+UK & 3 \\
Other (Europe and/or Asia) & 5 \\
\hline Type & 4 \\
\hline Clinical paper & 6 \\
Implementation of clinical project & 5 \\
Literature review & 1 \\
Research : mixed methods & 11 \\
Research : qualitative & 7 \\
Research : quantitative & \\
\hline Authors' background & 22 \\
\hline Critical care nursing & 7 \\
Medical-surgical nursing & 5 \\
Undefined & 9 \\
Papers including medical co- & \\
authors &
\end{tabular}


Table 2. Summary of properties and dimensionalization of patient deterioration with supporting citations

\begin{tabular}{|c|c|c|}
\hline Property & Selected examples from the literature (citation) & $\begin{array}{c}\text { Difference in ACU and ICU } \\
\text { nurses' definitions }\end{array}$ \\
\hline Evolving & $\begin{array}{l}\text { "Deterioration trajectory" (Donohue and Endacott, 2010, p. 15) } \\
\text { "Patient progress" (Johnstone et al., 2007, p. 221) } \\
\text { "The compensatory period before [deteriorating patients] become markedly } \\
\text { compromised" (Cioffi et al., 2010, p.190) }\end{array}$ & No \\
\hline Physiological & $\begin{array}{l}\text { "Disordered physiology" (Sharpley and Holden, 2004, p. 102) } \\
\text { "Malfunctioning of the body's homeostatic mechanism" (Liaw et al., 2011, p. } \\
\text { 298) } \\
\text { "The Modified Early Warning Scoring [was] calculated using the patient's vital } \\
\text { signs" (Donohue and Endacott, 2010, p. 11) } \\
\text { "Increasing or decreasing respirations may be the most important manifestation } \\
\text { of existing or developing critical illness" (Ryan et al., 2004, p. 1186) }\end{array}$ & $\begin{array}{l}\text { Reference of ICU nurses to the } \\
\text { Intensive Care Society's levels } \\
\text { of care (2002) not present in } \\
\text { ACU nurses' account }\end{array}$ \\
\hline Predictable & $\begin{array}{l}\text { "Guidelines had been given [to ACU nurses] that any patient at risk of } \\
\text { deterioration should be scored, with a suggested list of conditions that may put } \\
\text { patients more at risk" (Sharpley and Holden, 2004, p. 100)) }\end{array}$ & No \\
\hline Symptomatic & $\begin{array}{l}\text { "This [Early Warning Scoring System] was designed to measure patients' routine } \\
\text { physiological observations and provide an indication of their overall condition, } \\
\text { thus acting as a reliable indicator of impending critical illness." (Sharpley and } \\
\text { Holden, 2004, p. 99) } \\
\text { "The 'patient of concern' criterion is used mostly by nurses when they are } \\
\text { concerned about patients who do not show changes in physiological parameters } \\
\text { as outlined in set objective calling criteria" (Cioffi et al., 2010, p. 189) }\end{array}$ & $\begin{array}{l}\text { ICU nurses believe that } \\
\text { objective and quantifiable } \\
\text { indicators are reliable and } \\
\text { sensitive } \\
\text { ACU nurses tend to use } \\
\text { subjective and non-quantifiable } \\
\text { signs to recognize deterioration, } \\
\text { even before objective signs } \\
\text { begin to show }\end{array}$ \\
\hline
\end{tabular}

